\title{
A Teoria de Benveniste sobre a pessoalidade e seus desdobramentos na enunciação infantil
}

\author{
Benveniste's theory on personhood and its \\ unfolding in child enunciation
}

José Temístocles FerreIRA JÚNIOR

(Universidade Federal Rural de Pernambuco - UFRPE)

Valdir do Nascimento FLORES

(Universidade Federal do Rio Grande do Sul - UFRGS)

Marianne Carvalho Bezerra CAVALCANTE

(Universidade Federal da Paraíba - UFPB)

\section{RESUMO}

Neste trabalho, objetivamos discutir a teoria de Benveniste (1988 e 1989) sobre a categoria de pessoa na linguagem e examinar suas implicações na enunciação infantil. Para isso, iremos revisitar a abordagem enunciativa de Benveniste, destacando algumas questões correlacionadas à teoria da pessoalidade. Após isso, buscaremos apresentar dados ilustrativos para discutir a emergência e o funcionamento dos índices de pessoa na fala da criança. O corpus de que dispomos é formado por dados de interação envolvendo três crianças diferentes (e suas respectivas mães) em situações naturalísticas, presentes na pesquisa de Ferreira Júnior (2009). As análises dos nossos dados mostram que há mecanismos enunciativos subjacentes à fala da criança que comportam modos de apropriação do sistema da língua e de engajamento do sujeito na relação discursiva com o outro.

Palavras-chave: Enunciação infantil; Benveniste; categoria de pessoa; ancoragem subjetiva. 
José Temístocles Ferreira Júnior, Valdir do Nascimento Flores, Marianne Carvalho Bezerra Cavalcante

\section{ABSTRACT}

The purposes of this study are to discuss Benveniste's theory $(1988,1989)$ as regards the person category in language and to examine its implications in child enunciation. To this end, Benveniste's approach to enunciation will be revisited with the purpose of highlighting some issues related to the theory of personhood. After that, we will analyze illustrative data in order to discuss the emergence and functioning of person indices in child speech. The corpus consists of data drawn from Ferreira Júnior's previous research (2009) involving three children engaged in spontaneous interaction with their respective mothers. The results indicate that there are enunciative mechanisms underlying child speech that comprise modes of appropriation of the language system and modes of subject's engagement in discourse.

Key-words: Child enunciation; Benveniste; person category; subjective anchoring.

\section{Introdução}

A enunciação dos índices pessoais evidencia os movimentos de instalação da subjetividade no discurso. $\mathrm{Na}$ fala da criança isso não é, em linhas gerais, diferente. No entanto, há especificidades. Apoiados em postulados teóricos de Benveniste (1988 e 1989), segundo os quais o processo de enunciação dispõe de mecanismos que demandam continuamente do indivíduo uma tomada de posição como sujeito, buscaremos analisar de que modo a presença da criança na linguagem pode revelar a singularidade do sujeito na língua.

Para enunciar ou mesmo para compreender a enunciação do outro, é necessário que a criança se aproprie do sistema formal da enunciação e assuma as bases da linguagem condicionantes do ato enunciativo, quais sejam: temporalidade, espacialidade e pessoalidade. Nossa discussão aborda, de modo mais específico, a organização da categoria de pessoa.

Objetivamos investigar quais os desdobramentos que a teoria de Benveniste sobre a pessoalidade ${ }^{1}$ representa para abordagem da

1. A versão brasileira dos Problemas de linguística geral, de Émile Benveniste, traduz corrélation de personnalité por correlação de personalidade. Embora não se possa dizer que a tradução esteja errada, talvez seja mais adequado criar em português um neologis- 
emergência e do funcionamento dos índices de pessoa na enunciação infantil. Nosso corpus é formado por dados de interação envolvendo três crianças diferentes em situações naturalísticas, presentes na pesquisa desenvolvida por Ferreira Júnior (2009).

O corpus de que dispomos é constituído essencialmente por dados orais, coletados longitudinalmente, entre 0 e 36 meses de vida da criança e se integram aos corpora gerais do Laboratório de Aquisição de Fala e Escrita (LAFE) da Universidade Federal da Paraíba. As pesquisas desenvolvidas no LAFE têm se voltado para análise de dados presentes em gravações feitas em vídeos e em DVD de situações de interação entre díades mãe-bebê para discussão do processo de aquisição da linguagem. Trabalhamos aqui, especificamente, com as díades B, D e G, que, em termos quantitativos, somam 84 sessões já transcritas e compreendem a faixa etária de 00 a 36 meses de vida da criança. Nos dados a serem apresentados e analisados aqui, a faixa etária das crianças varia entre 12 e 31 meses. As situações são apresentadas em fragmentos, nos quais a idade das crianças é especificada e há uma breve descrição do contexto de interação. Optou-se por utilizar uma transcrição ortográfica. Os turnos de fala da criança e da mãe estão enumerados pela ordem em que são enunciados na cena analisada. Para diferenciar cada turno, utilizamos a letra "M" para identificar a fala da mãe e a letra "C" para especificar a fala da criança. Nossa análise possui um caráter qualitativo-interpretativo do processo de emergência e de funcionamento dos índices de pessoa na enunciação infantil.

Os resultados de nossas análises mostram que, através da observação dos mecanismos enunciativos presentes na fala da criança, é possível perceber diferentes modos de apropriação do sistema da língua e de instauração da singularidade do sujeito no discurso. Nesse sentido, os índices pessoais na enunciação da criança têm a propriedade de explicitar, dentro das regularidades que suportam a categoria de pessoa no discurso, as singularidades de cada sujeito na relação discursiva com o outro.

mo - pessoalidade - para evitar confusão com o termo técnico do campo da psicologia "personalidade". Benveniste quer, com o termo corrélation de personnalité, enfatizar algo que é do campo do linguístico, da categoria de pessoa, e não do psicológico, da personalidade. 


\section{Sobre linguagem e intersubjetividade}

Para compreender a teoria de Benveniste sobre a categoria de pessoa é fundamental recorrer aos conceitos de linguagem e subjetividade a ela correlacionados. A linguagem constitui, sem dúvida alguma, o elemento que cria a realidade do homem e o diferencia dos demais seres, garantindo-lhe condições para sua definição como sujeito e para sua singularização nas relações estabelecidas com outros indivíduos. É a linguagem o elemento que funda e instaura no homem a categoria de pessoa, condicional para o exercício da língua no contexto das diversas trocas sociais e discursivas. Mas o que é a linguagem? Essa foi, sem dúvida alguma, a pergunta que inquietou pensadores de diferentes áreas. Por seu raio de abrangência e suas facetas heteróclitas, a linguagem não se deixa apreender de modo integral, concreto, diretivo ou unívoco. Logo, a resposta a essa pergunta não é pacífica nem consensual.

No contexto da instituição da Linguística moderna, Ferdinand de Saussure se opôs diametralmente à visão da linguagem como nomenclatura por considerá-la simplista em numerosos aspectos. Para abordar a natureza multiforme e heteróclita da linguagem, Saussure se colocou no terreno da língua, tomando-a como parâmetro para o exame de todas as manifestações da linguagem (Cf.: Saussure, 2006: 16-17). Na superação dessa abordagem, Saussure definiu a língua como sistema de signos e procurou destacar o funcionamento interno do sistema linguístico, regrado por determinações próprias.

A visão de Saussure inspirou os trabalhos posteriormente desenvolvidos. Nesse contexto, as observações de Benveniste (1988 e 1989) contemplaram o fenômeno da enunciação. Mesmo inserido em um quadro avesso à consideração dos elementos externos ao objeto linguístico, Benveniste buscou incorporar à visão de Saussure os aspectos intersubjetivos e enunciativos da linguagem. Para o autor, "bem antes de servir para comunicar, a linguagem serve para viver." (1989: 222 - itálico do autor). Assim, a função da linguagem é, antes de tudo, garantir ao homem condições para sua constituição como sujeito no e para o exercício intersubjetivo, possibilitado por meio da língua. Com base no quadro enunciativo desenhado sob a perspectiva benvenistiana, a resposta à pergunta sobre o que vem a ser a linguagem insiste em seu caráter eminentemente intersubjetivo. 
Benveniste se afasta das abordagens que tomam a linguagem como instrumento de comunicação e sublinha os aspectos alteritários da linguagem e sua inerência à natureza humana. Essa propriedade fundamental da linguagem de assegurar ao homem o aparato necessário para sua definição como sujeito em oposição ao outro evoca, por isso mesmo, o caráter intersubjetivo da subjetividade. Para Benveniste, é em relação de contraste que o homem experimenta a consciência de si. Não se pode imaginar, segundo o autor, um homem concebendo a si e, depois, tentando conceber a existência do outro. Se a linguagem está na natureza humana, a alteridade figura como elemento constitutivo do sujeito.

Nesses termos, a realidade humana é marcada por uma intersubjetividade que é logicamente anterior e condicional à subjetividade. Embora Benveniste (1988 e 1989) não tenha formulado uma definição explícita para a intersubjetividade, estamos tomando-a, com base no conjunto dos textos propostos pelo linguista, como condição da presença do homem na linguagem na qual o $e u$ e o outro se pressupõem mutuamente.

As razões que justificam essa definição e os desdobramentos que ela representa para a enunciação infantil serão explorados ao longo de nossa discussão.

\section{A subjetividade na linguagem: aspectos gerais}

Diversas questões são suscitadas quando se busca compreender a visão benvenistiana acerca do sujeito e da subjetividade na linguagem. No texto "Da subjetividade na linguagem" há subsídios para o esclarecimento do modo com que o sujeito é concebido e tomado por Benveniste, destacando três pontos nevrálgicos para a compreensão da leitura que está sendo empreendida aqui: a) a noção de sujeito; b) a noção de subjetividade; c) o fundamento da subjetividade.

A noção de sujeito, em Benveniste, remete a uma realidade discursiva e, por isso mesmo, não coincidente com o sujeito da razão cujas experiências estão localizadas na consciência ou na racionalidade pragmática. 
Podemos encontrar, em Benveniste, a tese de que é o movimento de enunciação que recria indefinidamente o sujeito (Cf.: Benveniste, 1988: 285) e a produção de um enunciado supõe necessariamente um 'locutor', que instala de forma simultânea um 'interlocutor' com o qual enuncia em um dado contexto. É a enunciação o ponto de onde derivam e para o qual convergem todas as relações que criam, fundamentam e tornam possível a experiência do homem como sujeito na linguagem.

Em outras palavras, a enunciação traz à tona os elementos imprescindíveis à constituição subjetiva, quais sejam: linguagem/língua e intersubjetividade/subjetividade. Entre essas instâncias, verifica-se uma indissociabilidade incontornável. Se a enunciação entre sujeitos só é possível a partir da apropriação de um sistema linguístico, a linguagem e a intersubjetividade comparecem aí como instâncias que estão contidas sob a língua e sob a subjetividade. Nesse sentido, o ato enunciativo assegura a veracidade dessa constatação, pois a plenitude de seu funcionamento está condicionada à mobilização conjunta $\mathrm{e}$ integrada entre essas ordens.

Um segundo ponto a ser tratado aqui diz respeito à noção de subjetividade que, para Benveniste, não é mais que "a capacidade do locutor para se propor como "sujeito"' (Benveniste, 1988: 286). Isso nos faz entender que Benveniste observa a subjetividade do ponto de vista das condições de que o locutor dispõe e das quais se vale para proposição subjetiva. Essa capacidade, como já se destacou, está condicionada à linguagem e aos aspectos intersubjetivos que a linguagem evoca. $\mathrm{O}$ sujeito só encontra sentido para ser e condições para se propor sujeito no contexto das trocas que mantém e que estabelece com um outro sujeito através das instâncias de discurso assumidas pelo locutor na enunciação. Como se vê, duas outras noções são chamadas à discussão: "instância de discurso" e "locutor".

Um terceiro ponto - o fundamento da subjetividade - diz respeito ao status linguístico da "pessoa". Embora não se possa fazer equivaler os conceitos de subjetividade e pessoalidade, não se pode ignorar que, para Benveniste, as marcas que atualizam a representação do sujeito na língua estão sustentadas sobre a categoria de pessoa, correlacionada, por sua vez, a outras categorias enunciativas. 


\section{As categorias enunciativas da linguagem}

A discussão que Benveniste faz sobre a categoria de pessoa está inserida na relação entre referência e enunciação.

De acordo com Benveniste (1988), a língua dispõe de formas vazias quanto à referencialidade das quais o locutor se apropria para definir a si mesmo como "eu" e, ao mesmo tempo, para instalar na instância do discurso o seu interlocutor - o "tu". As formas linguísticas vazias de referência de que fala Benveniste são por ele denominadas "indicadores" aos quais poderíamos acrescentar - sem, com isso, imputar a Benveniste algo que seja externo ao seu raciocínio - a especificação "de subjetividade".

Os indicadores de subjetividade não têm a mesma natureza da dêixis - indício da remissão que a língua faz ao exterior contextual. Eles são sui-referenciais e sua existência está ligada ao ato enunciativo e tem por base o ponto de vista do sujeito que enuncia. É essa sui-referencialidade que nos leva a perceber que o sujeito está presente na língua.

Sob a noção de indicadores de subjetividade estão contempladas as categorias que indicam pessoalidade, temporalidade, espacialidade etc., atualizadas por meio de índices/indicadores específicos. Essas categorias estão ligadas ao eixo referencial criado e sustentado pela instância discursiva que as emprega. Vejamos:

- Categoria de pessoa: classe elementar da linguagem na qual se vê a experiência subjetiva dos sujeitos que se colocam na e pela linguagem. A categoria de pessoa se expressa nas línguas em um sistema de referências pessoais do qual cada locutor se apropria ao se enunciar e que, em cada instância de seu emprego, se torna único e irrepetível. Está centrada na oposição criada entre os integrantes do discurso "eu"/"tu" - "ele" (Cf. Flores, 2013, 123).

- Categoria de tempo: a categoria de tempo, juntamente com a categoria de pessoa, está ligada ao exercício da fala, se define e se organiza como função do discurso. Este tempo tem seu centro - um centro ao mesmo tempo gerador e axial - no presente da instância de discurso (Cf. Flores, 2013, 123). 
- Categoria de espaço: sistema de coordenadas espaciais organizado a partir de um ponto central, que é Eu, segundo modalidades variáveis. A categoria de espaço se presta também para localizar todo objeto em qualquer campo que seja, uma vez que aquele que o organiza está, ele próprio, designado como centro e ponto de referência (Cf. Flores, 2013, 123). É atualizada por meio de índices de ostentação (de maneira geral, os demonstrativos) e de localização espacial (os advérbios, por exemplo).

Todas essas categorias possuem caráter subjetivo e, em consequência, estão submetidas à dimensão intersubjetiva da linguagem. Essa dimensão intersubjetiva determina também o funcionamento em conjunto das categorias e a consideração dos aspectos correlacionais que as revestem, pois a enunciação de dada categoria implica a mobilização das outras duas e juntas formam o que estamos chamando aqui de categorias enunciativas da linguagem, necessárias à constituição e à instituição do sujeito no discurso.

Tomada como instância constitutiva da linguagem e como premissa subjacente à enunciação, a intersubjetividade se materializa no quadro das relações que se estabelecem entre as categorias enunciativas como um todo, conjugadas por uma instância discursiva, e nos índices que se apresentam no interior de cada categoria. Assim, as categorias enunciativas pressupõem um funcionamento conjunto e integrado, pois não se pode pensar a estruturação de uma sem considerar a relação que mantém com as demais, e esse aspecto veicula o caráter inter-relacional e alteritário das categorias.

Além disso, se considerarmos isoladamente cada categoria, veremos que os índices que as constituem são atualizados em uma relação por meio da qual ganham sentido. Se observarmos a categoria de espaço, por exemplo, percebemos que o índice "aqui" só pode ser concebido relativamente ao sintagma "aí" que, por sua vez, se relaciona ao índice "lá". Trata-se, portanto, de unidades cuja definição se dá em uma rede de elementos discretos mutuamente constituídos e dialeticamente relacionados. Essa mesma oposição relacional é perceptível nas categorias de tempo e pessoa. 
No interior das bases enunciativas, é possível perceber a oposição necessária ao funcionamento conjunto e à manutenção da ordem reversível da linguagem. A distinção entre essas categorias decorre do próprio exercício da língua, pois nelas estão situadas as experiências singulares de cada sujeito que se coloca na e pela linguagem por meio das instâncias de discurso mobilizadas no ato enunciativo. Segundo Benveniste (1988: 279), é na instância de discurso que a relação eu-tu $\leftrightarrow$ aqui $\leftrightarrow$ agora encontra suas determinações e é essa relação que forma a base axial para constituição do sistema da língua, do qual derivam outras classes linguísticas como "meu", "teu", "hoje", "amanhã", "neste lugar" etc.. Logo, a instância de discurso tenciona os aspectos sociais e individuais, gerais e específicos, regulares e singulares da linguagem, fundamentais à concretização do ato enunciativo. Para que o locutor se diga sujeito, ele deve tornar própria a regularidade subjacente ao sistema da língua que regula e fundamenta as relações interpessoais e, ao mesmo tempo, fornece os elementos indispensáveis à representação do sujeito. Assim, a intersubjetividade figura como fator determinante da linguagem.

Se a intersubjetividade se apresenta como condição para a linguagem, é no exercício enunciativo iniciado pelo outro que o infans, ao ser inserido pelo outro nas instâncias da linguagem, adquire o aparato necessário para sua definição e proposição como sujeito.

As determinações oriundas da intersubjetividade incidem sobre as relações entre os sujeitos e se projetam no modus operandi das categorias linguísticas, organizadas sob o eixo da instância enunciativa. É a partir desse eixo que o sujeito se apropria dos signos vazios de referencialidade espaço-temporal e pessoal, designando, no ato discursivo, a unicidade de sua representação em virtude das relações mantidas com o outro a quem dirige sua enunciação. A ordem intersubjetiva da linguagem é que propicia a significação dos índices de subjetividade, esvaziando-os de referencialidade para que o locutor, ao se identificar como sujeito, possa preencher o vazio referencial e venha a se propor sujeito na instância de discurso que assume.

É precisamente essa dimensão intersubjetiva da linguagem que permite ao locutor a assunção de unicidade subjetiva, por meio da mobilização de signos que, enquanto unidades semióticas em estado 
de dados lexicais discretos, estão providos de significação e vazios de referência e, quando assumidos na instância enunciativa, tornam-se plenos de referencialidade. Logo, a ordem intersubjetiva da linguagem assegura a plenitude funcional do uso dos indicadores de subjetividade no quadro da enunciação discursiva.

Em consequência, a autorreferência contida nas categorias de pessoalidade, temporalidade e espacialidade imprime um caráter único e particular à enunciação dos índices linguísticos que as atualizam.

A seguir, por razões teórico-metodológicas subjacentes à nossa pesquisa, daremos maior relevo à observação da categoria de pessoalidade, sem negligenciar, no entanto, a tríade em que está inserida e que lhe confere as características de sua especificidade.

\section{Da pessoalidade na linguagem}

A categoria de pessoa é instituída no quadro da enunciação, formalizado na língua pelo sistema de relações mantidas entre eu-tu $\leftrightarrow$ aqui $\leftrightarrow$ agora. Como já destacamos, na perspectiva de Benveniste, esse sistema está integrado à instância discursiva que o mobiliza, e dele derivam todos os índices autorreferenciais que não fazem outra coisa senão atualizá-lo no processo de conversão da língua em discurso. Nesse sentido, o exercício enunciativo da língua estrutura as relações opositivas que se estabelecem entre as pessoas do discurso, delimitando as diferenças existentes entre os papéis assumidos pelos participantes da cena discursiva ao mesmo tempo em que propicia, em seu próprio quadro, a constituição do homem como sujeito.

Por perceber o discurso como linguagem posta em ação entre parceiros (1988: 284), Benveniste rejeita a classificação constante em abordagens tradicionais que consideram a existência de três pessoas participantes da conversão da língua em uso: a primeira pessoa (aquela que fala), a segunda pessoa (aquela com que se fala) e a terceira pessoa (aquela de quem se fala), alinhadas em uma ordem constante sob um plano uniforme. Utilizando a enunciação como critério para classificação das pessoas do discurso, Benveniste postula a existência de duas redes de correlação opositiva na organização da categoria de pessoa: a primeira é a correlação de pessoalidade, que opõe "eu" e 
"tu”, pessoas efetivas, a "ele", não pessoa; a segunda rede diz respeito à correlação de subjetividade, que distingue "eu", pessoa subjetiva, de "tu", pessoa não subjetiva.

Falemos sobre o fundamento que sustenta a oposição na correlação de pessoalidade. Distintamente do que ocorre na relação "eu-tu", a terceira pessoa é desprovida da noção de pessoalidade e não se refere a uma pessoa que propriamente participa do ato de fala, comportando apenas uma indicação de enunciado sobre alguém ou sobre alguma coisa. Por isso, ao concordar com os gramáticos árabes para quem a terceira pessoa figura como "aquele que está ausente", Benveniste afirma que a terceira pessoa é, na verdade, a "não pessoa" (1988: 250251), aquela que não dispõe de condições para tomar a palavra ou mesmo assumir posição de destinatário da enunciação. Por essa via de raciocínio, não podemos tomar o "ele" como uma pessoa capaz de se esvaziar de pessoalidade, pois nele se verifica a ausência daquilo que qualifica propriamente o "eu" e o "tu": a unicidade da relação enunciativa e a inversibilidade dos papéis no ato enunciativo, da qual falaremos logo adiante.

A unicidade da relação eu-tu decorre da condição particular que reveste o próprio ato enunciativo: ao enunciar, a pessoa "eu" se dirige à pessoa "tu" em circunstâncias de pessoalidade, temporalidade e espacialidade muito singulares, submetidas à instância de discurso em que aparecem empregadas e onde são criadas. A instância de discurso assumida pelo locutor na enunciação é única e irrepetível por natureza, já a terceira pessoa, a não pessoa, pode se referir a uma infinidade de sujeitos ou a nenhum, não se prestando, portanto, à representação de uma pessoa efetivamente participante da situação enunciativa.

Outro aspecto apontado por Benveniste para destacar a dissimetria na relação $e u / t u \rightarrow$ ele diz respeito à inversibilidade dos papéis discursivos: ao enunciar, a pessoa "eu" instala em seu discurso um "tu", que, por sua vez, ao tomar a palavra, assume a posição de "eu" e torna o primeiro enunciador um "tu". No caso do "ele", esta inversão não é possível, justamente pelo fato de que "ele" não designa especificamente nada nem ninguém. "Ele" não pode ser assumido por um participante efetivo da ação enunciativa. É por essa razão também que "ele" pode tomar qualquer sujeito ou nenhum, mas quando comporta 
um sujeito este não é proposto como pessoa, exatamente pela falta de condições para participar da proposição enunciativa no quadro formal do discurso.

Por fim, aponta-se uma propriedade específica da não pessoa: é a única pela qual uma coisa pode ser predicada verbalmente. Em outros termos, é por meio da não-pessoa que "eu" e "tu" podem fazer remissão a assuntos diversos, abordar temas variados, trocar experiências, dinamizar o conteúdo do diálogo etc.; em suma, a não-pessoa pode ser rotulada como o "objeto da enunciação". A não pessoa se apresenta, nesse paradigma, como elemento essencial para definição e instituição da categoria de pessoa, justamente por provocar a clivagem necessária ao estabelecimento da oposição correlacional entre a pessoa e aquilo que ela não é. Assim, a categoria de pessoa é criada sob uma cisão fundante e determinante para sua existência enquanto categoria, pois, embora o "ele" não disponha de condições para tomar a palavra, não se pode enunciar sem que haja uma não pessoa, e o interstício que separa pessoa e não pessoa também propicia a realidade da correlação de pessoalidade.

Se por um lado, como já discutimos, o traço de pessoalidade está marcado em "eu" e em "tu" e ausente em "ele", por outro, é necessário destacar de que maneira as duas primeiras pessoas se opõem no interior do discurso. $\mathrm{O}$ par eu/tu é discriminado dentro da categoria de pessoa em uma correlação de subjetividade: ao tomar a palavra, a "pessoaeu" é instituída no discurso e instala, de forma relacional, opositiva e simultânea, a "pessoa não-eu", a quem direciona sua enunciação. Dessa forma, no interior da enunciação, instala-se a oposição constitutiva entre a primeira e a segunda pessoa. $\mathrm{O}$ "eu" só assume essa condição ao propor para um "tu" a função de interlocutor a quem dirige seu enunciado. Inversamente, quando o interlocutor toma o discurso, abandona imediatamente a condição de "tu" e passa a assumir a função locutor, propondo-se como "pessoa-eu" ao mesmo tempo em que demove o primeiro "eu" da condição de sujeito enunciador e o conduz à posição de "pessoa não-eu", iniciando um novo processo.

A partir desse ângulo, sob o plano das funções subjetivas assumidas e alternadas enunciativamente, torna-se possível delimitar as diferenças existentes entre a "pessoa-eu" e a "pessoa não-eu”: O "eu" 
ocupa, segundo Benveniste, uma posição de interioridade em relação ao enunciado proposto e de exterioridade em relação ao "tu", com quem estabelece o diálogo. Entretanto, a observação de Benveniste a respeito da posição de transcendência que "eu" exerce sobre o "tu" não deve suprimir os caracteres da enunciação, e o que entra em jogo é a formalidade do ato enunciativo, executado por um locutor que, ao proferir "eu" na instância enunciativa de que se vale, obrigatória e simultaneamente, instala um "tu" a quem dirige a sua enunciação, e nessa relação não se verifica simetria, mas há sempre implicação em virtude da condição de alocução a que todo processo enunciativo está submetido.

Logo, a enunciação proposta pela "pessoa-eu" supõe sempre a "pessoa não-eu", e ambas só existem na oposição que estabelecem com a não-pessoa, em uma relação de implicação incontornável ao plano das formas, determinada pelo ato de enunciar.

$\mathrm{Na}$ análise que empreende das relações de pessoa no verbo em diferentes línguas, Benveniste (1988) afirma o seu desacordo com a classificação herdada da gramática grega que discrimina três pessoas para o quadro da flexão verbal com base no conjunto das posições presentes nas formas verbais. Essa enumeração, entretanto, não elucida, conforme Benveniste, o princípio que rege a oposição entre as pessoas e planifica relações entre índices que abrigam entre si oposições salientes no quadro do discurso. Nos idiomas observados pelo linguista (semítico, turco, ugro-fínico, húngaro, georgiano, caucásico, dravídico, esquimó, línguas ameríndias, indo-europeu etc.), há uma extensa lista de exemplos de flexões verbais que acentuam a dissimetria das relações entre as pessoas: com algumas nuanças, os índices que marcam a pessoalidade linguística nas línguas analisadas se ausentam nas formas que designam a terceira pessoa, o que torna evidente a impertinência de uma classificação uniforme na descrição das pessoas verbais.

Somado a isso, outro fato observado por Benveniste para sublinhar os desajustes da enumeração clássica das pessoas do discurso diz respeito à ausência, na terceira pessoa, das características que predicam a relação "eu-tu": a unicidade (posto que o "eu" que enuncia e o "tu" a quem o "eu" enuncia são sempre únicos) e a inversibilidade, determinada pelo caráter reversível das relações que "eu" e "tu" estabelecem na 
tomada da palavra. Como já destacamos, no paradigma benvenistiano, o "ele" pode indicar qualquer sujeito ou não comportar nenhum, mas nunca está apto à proposição como pessoa, pois não compartilha das propriedades inerentes às pessoas que participam do ato de conversão da língua em discurso.

A expressão da categoria de pessoa também pode ser feita a partir da classe dos pronomes, itens linguísticos responsáveis pela formalização dos índices subjacentes ao emprego da língua. Nesse aspecto, em um texto voltado à discussão da natureza dos pronomes, Benveniste (1988: 277) afirma que a universalidade dessa classe em diferentes línguas sugere que ela representa, a um só tempo, "um problema de linguagem e um problema de línguas, ou melhor, só é um problema de línguas por ser, em primeiro lugar, um problema de linguagem." (os itálicos são nossos). É como fato de linguagem que Benveniste buscou abordar a questão suscitada pelos pronomes, mostrando que eles não constituem uma classe homogênea e uniforme.

Por tratar os pronomes como fatos de linguagem, Benveniste expôs essa classe (e todas as suas subclasses, como os demonstrativos, indefinidos, possessivos, pessoais etc.) ao domínio da enunciação e aos elementos linguístico-discursivos que nela estão implicados e sob ela encontram-se amalgamados. A mobilização do sistema pronominal no ato enunciativo comporta uma série de relações entre instâncias de diferentes grandezas que juntas sustentam a representação do sujeito na língua e apontam para o caráter alteritário, intersubjetivo, interrelacional e discursivo das relações de pessoa.

A passagem da língua ao discurso, na enunciação dos pronomes, veicula e abriga relações entre instâncias que só adquirem sentido na oposição que as liga. Para dizer "eu", por exemplo, o locutor precisa se reconhecer no contraste essencial que o separa de "tu" e "ele". Esse contraste é dado, de início, pela comunicação intersubjetiva e pelas esferas que a tornam possível, a saber: a linguagem e a intersubjetividade. Ambas só existem no quadro das oposições contidas no exercício enunciativo da língua, e é nesse quadro que o sujeito localiza suas determinações a partir do reconhecimento do lugar que ocupa na instância do discurso. Assim, os índices pronominais trazem à tona toda realidade ensaiada pelo sujeito no ato enunciativo. Com base na 
análise do pronome "eu", Benveniste procurou refletir sobre a natureza dos índices de pessoa. Conforme o autor:

Entre $e u$ e um nome referente a uma noção lexical, há não apenas as diferenças formais, muito variáveis, impostas pela estrutura morfológica e sintática das línguas particulares. Há outras, que se prendem ao próprio processus da enunciação linguística e que são de uma natureza mais geral e mais profunda. $\mathrm{O}$ enunciado que contém eu pertence a esse nível ou tipo de linguagem a que Charles Morris chama pragmático, e que inclui, com os signos, aqueles que os empregam. (1988: 278 - itálicos do autor)

Mesmo tomado como item lexical, não há possibilidade de formular para o clítico pessoal "eu" uma definição uniforme e objetiva que sirva igualmente para todos os locutores que dele precisam se valer no ato de fala. $\mathrm{Na}$ ausência de condições para definir o signo "eu" como uma classe constante de referência, cada emprego de "eu" deve ser tomado na unicidade da instância de discurso em que aparece. Essa observação deve ser dimensionada: se, por um lado, o índice "eu" é desprovido de referencialidade objetiva capaz de predicá-lo sumariamente no léxico da língua, por outro, sua referência é preenchida pelo locutor na própria enunciação linguística, ao se identificar como pessoa na instância de discurso que assume. Ressaltando-se algumas particularidades, essa análise é extensiva ao pronome "tu".

Mas o linguista não ignora a condição de forma sob a qual se apresentam os pronomes "eu" e "tu". Pelo contrário, é a partir da realidade formal que Benveniste busca apreender a realidade discursiva dos pronomes pessoais, na dupla instância conjugada que a enunciação funde e faz suscitar, qual seja: no ato de fala proposto pela pessoa "eu", há um "eu" como referente (aquele que refere) e um "eu" referido e, igualmente, um "tu" a quem o locutor se refere e um "tu" que aparece representado no discurso proferido por "eu". Benveniste sintetiza essa descrição da seguinte forma:

Há, pois, nesse processo uma dupla instância conjugada: instância de eu como referente, e instância de discurso contendo $e u$, como referido. A definição pode, então, precisar-se assim: eu é o "indivíduo que enuncia a presente instância de discurso que contém a instância linguística eu". Consequentemente, introduzindo-se a situação de "alocução", obtém-se 
uma definição simétrica para $t u$, como o "indivíduo alocutado na presente instância de discurso contendo a instância linguística $t u$ ". Essas definições visam $e u$ e $t u$ como uma categoria de linguagem e se relacionam com sua posição na linguagem. (Benveniste, 1988: 279)

A bipartição da instância de pessoa já havia sido observada por Benveniste no texto sobre a "Estrutura das relações de pessoa no verbo". Na linha de raciocínio que desenha nesse texto, Benveniste destaca que a cisão entre as instâncias ocorre em virtude do exercício enunciativo da linguagem: "Nas duas primeiras pessoas, há ao mesmo tempo uma pessoa implicada e um discurso sobre essa pessoa." (1988: 250). Observa-se aí uma separação entre a pessoa que fala, implicada no ato enunciativo, e a pessoa representada no discurso. Como dissemos, essa separação se repete na concepção do "tu", pessoa a quem o sujeito enunciador se dirige e que é representada através de marcas específicas que lhe são atribuídas no discurso proposto por "eu”. Nesse caso, o ato de enunciar traz consigo um pressuposto condicional e irredutível: alguém fala a um outro e mobiliza, para isso, uma estrutura formal apropriada à representação das pessoas e dos elementos envolvidos no discurso.

Ao operar a bifurcação das representações das pessoas no discurso, Benveniste, em nossa opinião, autoriza a percepção de outros signos, os nomes por exemplo, que podem ser mobilizados pelo sujeito para automarcação.". Essa não é uma interpretação óbvia e pode mesmo, em um primeiro momento, parecer ir de encontro à teoria $\mathrm{d}$ Benveniste. No entanto, há um segundo argumento que pode validar nossa aceitação da classe dos nomes como signos aptos à indicação da pessoa: a relação entre as formas e os sentidos na linguagem.

Se a relação dada entre forma e sentido na enunciação da língua não é unívoca, a referência à pessoa no ato enunciativo é passível de flutuação, e os nomes podem se prestar à sustentação da categoria de pessoalidade, funcionando como índices de subjetividade. A hipótese levantada aqui não é movida apenas pelo aparato teórico escolhido para embasar a reflexão em torno da realidade que a categoria de pessoa abriga. Como veremos, a observação da enunciação infantil testemunha em favor da premissa de que os nomes e os nomes próprios funcionam como índices de pessoalidade recorrentes na fala da criança, com 
algumas particularidades: preservam a característica de unicidade da pessoa (própria, como já destacamos, à relação “eu-tu”), mas retêm (sem suprimir) o traço de inversibilidade.

Embora Benveniste (1988 e 1989) não tenha destacado explicitamente a propriedade da classe dos nomes para atualização da oposição entre as pessoas do discurso, temos defendido, com base em sua própria reflexão sobre a forma e o sentido na linguagem (Cf. "A forma e o sentido na linguagem"), que os nomes figuram como uma classe apta à representação da categoria de pessoa. Essa hipótese ganha força se considerarmos as interações dialógicas iniciais mantidas entre a mãe e a criança, nas quais é possível perceber uma abundância de nomes usados para fazer referência aos participantes e aos integrantes do ato enunciativo. Basta considerarmos enunciados como "O bebê tá com sono?", "A mamãe ama muito o bebê" ou "Cadê o nenê da mamãe?". Exemplos dessa natureza podem ser encontrados no corpus descrito e analisado na pesquisa de Ferreira Júnior (2009) em vê-se que, na relação mãe-bebê, é recorrente o uso de marcas linguísticas de terceira pessoa (como os nomes "bebê", "nenê", "mamãe", "papai" e suas variantes. Além deles, o uso de nomes próprios para indicar as pessoas do discurso também é bastante comum.) para fazer referência aos participantes da cena enunciativa.

Em suma, é possível afirmar que a categoria de pessoa é criada pelo ato enunciativo e pode se apresentar através de diferentes modos e em diferentes classes de palavras: nas desinências e nas flexões verbais, nos pronomes (e em suas subclasses) e nos nomes e nos nomes próprios. Como observa Benveniste (1988), não importa se os índices que atualizam essas classes figurem explicitamente no discurso ou aí permaneçam implícitos. Não é preciso, por exemplo, que um enunciado contenha "eu" para que aquele que fala esteja implicado e seja considerado em seu discurso. $\mathrm{O}$ ato enunciativo coloca em cena os termos que viabilizam a sua consecução, mas põe em constante tensão aquilo que nele está implícito e o que tende a explicitar. Iremos considerar esse aspecto com base na enunciação infantil para, então, redimensionar os modos de representação da criança na linguagem e pensar um modelo de análise que comporte a singularidade de sua constituição e instituição subjetiva no discurso. 


\section{A presença dos índices de pessoa na enunciação infantil}

À semelhança das outras categorias, o caráter intersubjetivo da linguagem, necessário à manutenção das trocas interpessoais, determina o funcionamento integrado entre as formas que se prestam à representação das pessoas do discurso. Para resolver o problema da comunicação intersubjetiva, o sistema dos índices pessoais de cada língua disponibiliza ao locutor um repertório de formas desprovidas de referência, que devem, por isso mesmo, ser preenchidas na instância de discurso em que aparecem empregadas. Logo, a significação dos índices de pessoa não é dada de forma objetiva e nem se submete à lógica das condições de verdade, pois sua realidade está atrelada à instância de discurso assumida pelo locutor no ato de fala.

Na perspectiva benvenistiana, se cada locutor lançasse mão de uma marca linguística diferente para sua autoindicação no discurso, a comunicação seria impossível, pois a diversidade de formas para representar o locutor que assume a palavra colocaria em risco a estabilidade do mecanismo enunciativo e isso abalaria sobremaneira as relações estabelecidas entre as pessoas no discurso, colocando em xeque a possibilidade de constituição subjetiva. Como, então, forjar um sistema capaz de atender à pluralidade dos indivíduos que dele se valem sem suplantar a unicidade de cada sujeito que nele busca meios para se constituir? O caminho para saída do impasse é dado pelo sistema dos indicadores de pessoa que, em virtude da generalidade que evoca, extrapola uma indicação de pessoa específica e comporta, ao mesmo tempo, a singularidade da instância discursiva que dele faz uso. Por isso (e paradoxalmente) esse mesmo sistema permite que o sujeito falante institua a sua especificidade no domínio social da linguagem, ao transformar a virtualidade dos índices do paradigma de pessoa em realidade discursiva única que designa aquele que toma a palavra no instante da enunciação.

Se a substância que preenche os índices de pessoa advém do discurso, é preciso que o falante ocupe um lugar na instância da enunciação antes de se valer das formas linguísticas apropriadas à representação das pessoas. O fato de a criança enunciar o que quer que seja já é suficiente para dizermos que foi deflagrado o processo de constituição subjetiva do infans, e o movimento dessa constituição seguirá uma 
trajetória única em direção às representações dos papéis assumidos e alternados no discurso.

Por esses termos, o ato de ocupação de um espaço na estrutura enunciativa da língua figura como condição imprescindível para a organização da categoria de pessoa no discurso, mas como considerar essa organização para representar aqueles que ainda não (se) enunciam? Ou ainda: como descrever o sistema dos índices de pessoa diante de um quadro de aquisição da linguagem em que a ocupação das bases enunciativas está velada no discurso e em vias de constituição?

Naturalmente, não se pode abordar o funcionamento da categoria de pessoa na enunciação infantil pelo mesmo prisma com que é observada na fala do adulto, mas o statu nascendi ${ }^{2}$ da linguagem contém em potência a matéria-prima das relações permanentemente estabelecidas entre o homem, os sistemas simbólicos e o outro, e aponta, nesse aspecto, para a necessidade de formulação de um modelo teórico e analítico ajustado às especificidades da fala da criança. Com isso, afirmamos que os elementos indispensáveis ao arranjo da categoria de pessoa estão presentes desde sempre na enunciação da criança, mas a forma com que esta se representa nas estruturas linguísticas é muito particular e deve ser dimensionada a partir do processo de enunciação.

Por estar implícita ao funcionamento da enunciação, a organização da categoria de pessoa está fadada à marcação explícita dos papéis discursivos que representa nos enunciados de uma língua dada, e o processo enunciativo projeta constantemente nas formas linguísticas os elementos que nele estão contidos. Trata-se de um jogo contínuo entre a explicitação e o escamoteamento, e é nesse jogo que a criança negocia com a alteridade/heterogeneidade ensaiada sob o caráter homogeneizante da língua-discurso. A emergência dos índices de pessoalidade em cada instância de fala enunciada pela criança corrobora a veracidade dessa assertiva.

Ao tratar das questões relativas à linguagem, Benveniste (1988 e 1989) não se deteve sobre as especificidades da enunciação infantil, mas em seus textos deixou transparecer alguns indícios que nos permitem vislumbrar tais especificidades. Em uma entrevista concedida a 
Pierre Daix ${ }^{3}$, Benveniste (1989) aborda pontos suscitados no modelo chomskiano e argumenta em favor da inventividade da enunciação linguageira, afirmando que "todo homem inventa sua língua e a inventa durante toda a sua vida" (p. 18). No entanto, fundamentando-se no caráter intersubjetivo da linguagem, Benveniste (1989: 20) assegura que "qualquer pessoa pode inventar uma língua, mas ela não existe (...) desde que não haja dois indivíduos que possam manejá-la como nativos". Em outros termos, a língua que o homem inventa só tem valor no quadro das relações estabelecidas com outro homem.

Se o homem, de fato, inventa sempre a sua língua, então não podemos pensar em um processo acabado de aquisição de linguagem, mas, pelo contrário, podemos pensar que a cada vez que o indivíduo enuncia revela as mudanças da relação do sujeito com a língua e com sua própria subjetividade (Cf. Silva, 2009). A língua figura como condição de e meio para criação de toda a realidade que sustenta as relações entre a criança e seus parceiros enunciativos.

Se a criança só atinge as relações humanas por meio da língua, é no quadro dessas relações que a inventividade da enunciação infantil deve ser considerada. A questão que parece fundamental, e que foi apontada por Benveniste no decorrer dessa entrevista (Cf.: Benveniste, 1989: 19), é perceber o modo com que cada locutor fabrica sua língua. Assim, ao voltarmos a nossa atenção para a emergência dos índices de pessoa na fala da criança, é preciso dimensionar a singularidade dessa emergência a partir das relações que se estabelecem entre a criança e a língua e a criança e seu(s) parceiro(s) enunciativo(s). O modo com que a criança institui a originalidade de sua invenção linguística só pode ser apreendido no quadro do discurso, e essa constatação é extensiva ao uso dos índices de pessoa.

O discurso é o lugar em que as oposições entre as pessoas são definidas e marcadas no repertório das formas dadas pela língua. Logo, é também no discurso e por meio do discurso que a criança adentra na lógica que sustenta a categoria de pessoa. Na síntese das considerações feitas até aqui a partir do pensamento benvenistiano, podemos propor um modelo para ilustrar a construção/organização da categoria de pessoa na enunciação e os elementos que nela estão envolvidos e 
implicados. No ato enunciativo, são tencionados elementos que tendem à explicitação e elementos que figuram como suporte para o processo de conversão da língua em discurso.

A atividade enunciativa expõe a mobilização conjunta de diferentes ordens que convergem para a instância de discurso, canal que funde, por meio de índices próprios, sujeito e língua, pessoa e linguagem. $\mathrm{Ou}$ seja, a partir da enunciação, cria-se uma realidade discursiva na qual os índices de pessoa estão inseridos para designar os participantes do ato de discurso. Como dissemos logo acima, a presença de tais índices nos enunciados proferidos pelo locutor é prescindível, pois mesmo que não apareçam explicitamente na fala daqueles que enunciam, os índices de pessoalidade estão irrevogavelmente implicados na instância de discurso assumida pelo locutor. Assim, a capacidade de proposição subjetiva do locutor não deve ser mensurada apenas pelas marcas de subjetividade manifestas na superfície linguística do enunciado ou mesmo se limitar à explicitação do discurso. "É portanto verdade ao pé da letra que o fundamento da subjetividade está no exercício da língua." (Cf.: Benveniste, 1988: 288).

A partir de tais premissas, em Ferreira Júnior (2009), foi desenvolvida a pesquisa sobre a emergência dos indicadores de pessoa na fala da criança durante o processo de aquisição da linguagem. Nesse estudo, é mostrado de que maneira a mãe desdobra a sua enunciação em dois eixos para dar lugar à representação da criança no discurso. O primeiro eixo de referência às pessoas da enunciação está presente na fala atribuída materna (em manhês). Nele, o sujeito da mãe pode ser representado em, pelo menos, três instâncias discursivas diferentes: o sujeito enunciador de suas próprias produções, aquele que fala em nome dele mesmo e que Ferreira Júnior (2009: 55) denominou "SE1"; o sujeito enunciado pela suposta enunciação atribuída ao infans (chamado pelo autor de "SE2"), que funciona também como objeto do discurso materno; e o sujeito/interlocutor $\left(\mathrm{SI}^{1}\right)$ que, na enunciação atribuída ao infans, exerce um papel interlocutivo e se confunde com a segunda pessoa do espaço discursivo. ${ }^{4}$ Vejamos os fragmentos apresentados pelo autor (Cf.: Ferreira Júnior, 2009: 55-56) para sustentar seus apontamentos:

4. Essa constatação confirma alguns apontamentos feitos por Cavalcante (1999) a respeito da existência de instâncias subjetivas distintas na fala atribuída materna. 
FRAGMENTO 015: DÍADE B, IDADE: 12meses e 21 dias

O bebê está sobre o tapete e a mãe está organizando as roupas.

$01 \quad \mathrm{M} \quad$ (...) Quer dormir, quer? (em manhês)

02 C Qué, qué

03 M Quer? Mamãe bota a rede pra você dormi $(\ldots) \rightarrow\left(\mathbf{S E}^{2}\right)$ (em manhês) deixa eu botar a rede pra gente dormir aqui na rede $(\ldots) \rightarrow\left(\mathbf{S E}^{\mathbf{1}}\right)$

04 C Mi, mi

FRAGMENTO 02: DÍADE B, IDADE: 12 meses e 15 dias

A mãe está trocando as roupas do bebê

01 M Cadê Vitor? Cadê o nenê de mamãe? Cadê ele? (em manhês)

02 C (Mexe os braços e olha para mãe)

03 M Cadê o menino de mamãe, Tu (...) (SI ${ }^{1}$ ) (em manhês) Achou, mamãe. Achou. (...)

FRAGMENTO 03: DÍADE B, IDADE: 12 meses e 15 dias

A mãe está trocando as roupas do bebê

01 M Cadê o passarinho, Vitor? Cadê o passarinho? (SI ${ }^{1}$ ) (em manhês)

02 C (Vocaliza)

03 M Cadê, Vitor? (SI ${ }^{1}$ ) (em manhês)

Como podemos perceber no fragmento 01, no turno 03, a fala materna representa o sujeito enunciador de duas formas: com a marca de terceira pessoa e a referência de primeira "a mãe bota", típica função $\mathrm{SE}^{2}$, e no turno seguinte a atualização da primeira pessoa discursiva é feita por meio do pronome "eu". Verifica-se, pois, aí alguma oscilação nas formas linguísticas de referência à primeira pessoa discursiva, a quem se atribui o mesmo papel de agente da ação indicada na oração dos sintagmas "a mãe bota" e "deixa eu botar".

Ferreira Júnior (2009), então, afirma que essa mesma oscilação se aplica à função interlocutiva conferida à criança nos fragmentos 2 e 3 .

5. Os fragmentos apresentados aqui receberam outra numeração para atender à didaticidade necessária à leitura. 
No turno 03 do fragmento 02 , essa função é posta em cena por meio de um indicador pronominal de segunda pessoa ("Tu"); já no fragmento seguinte, nos turnos 01 e 03, a representação da segunda pessoa se dá nas formas nominais vocativas de "Vitor". Note-se que nas duas instâncias enunciativas, a atualização dos participantes do discurso é feita de maneira deslizante.

Logo podemos ver, nesses fragmentos de fala materna disponíveis em Ferreira Júnior (2009), que a representação do sujeito/mãe desdobrase em dois tipos de proposição subjetiva em função de um terceiro elemento intersubjetivo: o sujeito enunciador é deslocado para posição de sujeito enunciado e, ao mesmo tempo, sua enunciação se destina a um interlocutor atualizado pelos índices de pessoa que se referem à mãe, mas que, por vezes, substituem a pessoa do bebê.

Esse modo de funcionamento de representação do sujeito materno pode ser esquematizado da seguinte forma: $\mathrm{SE}^{1 /} / \mathrm{SE}^{2} \rightarrow \mathrm{SI}{ }^{1}$, em que "SE ${ }^{1}$ " refere-se à função de "sujeito enunciador, aquele que enuncia com marca de primeira pessoa", "SE ${ }^{2 "}$ " diz respeito à função de "sujeito enunciado pela enunciação que a mãe atribui ao infans, e é marcado com por meio de formas linguísticas de terceira pessoa para se referir à primeira pessoa" e "SI " remete à posição de "sujeito interlocutor aquele, que na enunciação atribuída materna, exerce papel de segunda pessoa e aparece marcado com vocativos ou marcas de segunda pessoa". A ocupação dessas posições enunciativas alterna-se a cada enunciação.

Do mesmo modo, as representações do bebê nas enunciações atribuídas da mãe também passam por alterações visíveis e, em algumas situações, confunde-se com a própria representação materna nas estruturas linguísticas. $\mathrm{Na}$ cena enunciativa delineada pelo manhês, parte-se de uma particularidade que não pode ser ignorada: o bebê é sujeito enunciador de uma enunciação que não é sua, ou seja, é-lhe atribuído, mesmo que de forma provisória, o lugar de enunciador suposto, o qual é enunciado em primeira pessoa do discurso. A este enunciador suposto Ferreira Júnior denominou "ES ${ }^{1 "}$ ".

Em grande parte das situações enunciativas observadas por Ferreira Júnior (2009), o sujeito/criança comparece à fala materna com a marca linguística de terceira pessoa, seja com sintagmas nominais, seja 
com sintagmas pronominais e para identificar esse tipo de ocorrência o autor utilizou a abreviação "ES ${ }^{2 "}$. Mesmo se tratando de uma fala atribuída ao bebê, em algumas situações este é tomado como interlocutor de sua própria enunciação e, nesse caso, Ferreira Júnior chamou essa posição de "SI "

Ora, pode-se constatar que a representação do infans no manhês, do mesmo modo que a representação materna passa por essas três instâncias distintas de proposição subjetiva: o enunciador suposto propõe-se como sujeito ora em primeira pessoa, ora em terceira, ao mesmo tempo em que instala seu interlocutor (que, nessa fala atribuída, pode ser o próprio bebê ou a mãe). O esquema agora passa a ser: ES ${ }^{1} / \mathrm{ES}^{2} \rightarrow \mathrm{SI}^{2}$.

FRAGMENTO 04: DIADE B, IDADE: 12 meses e 15 dias A mãe e o bebê estão conversando (em manhês)

$\begin{array}{lll}01 & \text { M } & \text { "Olha o pintinho, mãezinha!" } \rightarrow\left(\text { ES }{ }^{1}\right) \\ 02 & \text { M } & \text { "Bora brincar, mamãe?" } \rightarrow(\text { ES }\end{array}$

FRAGMENTO 05: DÍADE B, IDADE: 12 meses e 15 dias A mãe está trocando as roupas do bebê (em manhês)

01 M Cadê Vitor? Cadê o nenê de mamãe? Cadê ele? $\rightarrow\left(\right.$ ES $\left.^{2}\right)$

02 C (Mexe os braços e olha para mãe)

03 M Cadê o menino de mamãe, Tu (...) Acho, mamãe. Acho. (...)

04 M Eu tô aqui, mamãe, eu tô aqui (em falsetto) $\rightarrow\left(\right.$ ES $\left.^{\mathbf{1}}\right)$

FRAGMENTO 06: DIADE B, IDADE: 12 meses e 15 dias A mãe e o bebê estão conversando (em manhês)

$01 \quad$ M “Olha o pintinho, mãezinha!" $\rightarrow\left(\mathbf{S I}^{2}\right)$

02 M "Bora brincar, mamãe?" $\rightarrow\left(\mathbf{~ S I ~}^{2}\right)$

Em todos os fragmentos acima, o sujeito infantil supostamente enuncia. No fragmento 4, a atualização dessa função subjetiva se dá nos sintagmas verbais presentes nos dois turnos, pois neles o sujeito suposto convida o interlocutor materno a participar de duas ações "Olha o pintinho" e "Bora brincar". Notadamente, no plano do discurso, a função de interlocutor é preenchida pelo sujeito materno nos sintagmas "mamãe" e "mãezinha". 
No fragmento 05, no turno 01, o enunciador suposto fala de si mesmo em terceira pessoa nos segmentos destacados "Cadê Vitor? Cadê o nenê de mamãe? Cadê ele?". É como se ambos, o bebê e a mãe, abstraindo-se da cena enunciativa de que efetivamente participam, estivessem falando de um terceiro participante, que neste caso se refere ao próprio bebê. Isso implica um deslocamento radical, pois o bebê, que se movimentava nas funções de sujeito enunciado, suposto enunciador e interlocutor, ocupa agora a posição de objeto do discurso da díade.

No mesmo fragmento, no turno 04, o enunciador suposto é enunciado em primeira pessoa dizendo à mãe "eu tô aqui", enquanto que a mãe ocupa aí a posição de interlocutor desse sujeito que está sendo enunciado.

No manhês, a representação da pessoa materna ocorre nos moldes

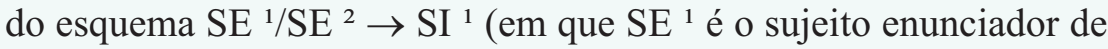
fato e, na enunciação, se propõe como sujeito; $\mathrm{SE}^{2}$ é o sujeito materno sendo enunciado na enunciação atribuída ao bebê; SI é remete ao deslocamento do sujeito materno para posição de interlocutor). Enquanto que para representar a criança e garantir-lhe um espaço na enunciação, a mãe se utiliza de recursos simbolizados no seguinte esquema: ES ${ }^{1} / \mathrm{ES}^{2} \rightarrow \mathrm{SI}^{2}$ (no qual ES ${ }^{1}$ é o enunciador suposto; ES ${ }^{2}$ representa o sujeito/criança em terceira pessoa; SI ${ }^{2}$ diz respeito à ocupação da função interlocutiva do parceiro enunciativo, nesse caso a mãe).

Portanto, do ponto de vista da enunciação de primeiro eixo, o infans se vê representado e sustentado em diversos lugares no discurso. Por meio da observação de comportamentos diversos do infans (tais como troca de olhares com a mãe, vocalizações, balbucios, etc) frente ao discurso materno, podemos perceber que o sujeito não está alheio ou passivo à cena enunciativa, mas está em processo de constituição.

O segundo eixo de referência às pessoas do discurso está localizado, de acordo com Ferreira Júnior (2009), na fala materna normal em substituição à fala em manhês. Nele, a mãe pode se enunciar em primeira pessoa com a marca linguística de primeira pessoa $\left(\mathrm{Se}^{1}\right)$ ou com a marca linguística de terceira pessoa $\left(\mathrm{Se}^{2}\right)$ e toma o bebê como seu interlocutor (SI) ao mesmo tempo em que fala de um objeto discursivo constitutivo do próprio ato enunciativo. Nesse caso, verificou-se, na estrutura enunciativa, a disjunção entre o sujeito locutor (a mãe) e 
o interlocutor (o bebê) tomado de forma implícita ou explícita (no uso de vocativos). Vejamos os exemplos mostrados por Ferreira Júnior (2009: 59 e 60):

FRAGMENTO 07: DÍADE G, IDADE: 31 meses e 00 dias A mãe e o bebê estão brincando na área externa da casa

01 M Eu pensei que fosse pequeno quando eu (pausa) quando eu pedi pra Jorginho encher. Eu disse: "Meu Deus, onde é que eu vou guardar isso?" (Se ${ }^{1}$ )

02 C (Continua retirando os brinquedos da piscina)

$03 \quad$ M Aline gosta de nadar? (SI)

04 C Gosta. Mamãe e papai também gosta.

FRAGMENTO 08: DÍADE D, IDADE: 24 meses e 24 dias

A mãe e o bebê estão no sofá. A mãe está dando comida ao bebê.

01 M Tu espera um pouquinho? (SI)

02 C (olhando para o televisor)

03 M Amanhã a gente vai pra praia

$04 \mathrm{M} \quad$ (olhando para o televisor)

FRAGMENTO 09: DÍADE G, IDADE: 31 meses e 00 dias A mãe e o bebê estão indo para área externa para brincar.

01 M Vai tirano os brinquedos pra mamãe, ajuda ( $\left(\mathbf{S e}^{2}\right)$

02 C Eita (balança o brinquedo e se molha). Não, não.

03 M Tu ajuda não? (SI)

04 C O que o carro faz? Pega os brinquedos de Aline

Nestes fragmentos acima, é perceptível que a mãe não mais usa a fala melódica e infantilizada para se dirigir à criança, como o fez nas situações anteriormente mostradas por Ferreira Júnior (2009). No fragmento 7 , no turno 01 , a mãe comparece à cena enunciativa na posição de sujeito enunciador de suas próprias produções e se representa em primeira pessoa, seja nos pronomes, seja nos verbos, como se vê nos trechos "Eu pensei”, "eu pedi", "eu disse" e "eu vou”. Logo, instala-se nessa mesma cena a criança como interlocutor da mãe, porém prevalece ainda a marca de terceira pessoa no uso do dêitico nominal "Aline" (turno 03). Em seguida, a criança, em resposta à pergunta feita pela mãe no turno 03 , representa-se também com marca de terceira pessoa no uso do verbo "gosta" (turno 04). 
Porém, no fragmento 09 (turno 03), a mesma mãe enuncia um índice de segunda pessoa o "tu" para fazer um questionamento à filha, que, por sua vez, utiliza no turno seguinte novamente seu nome próprio para fazer referência a si mesma no discurso. É interessante notar que seu enunciado surge agora não exatamente em resposta à pergunta feita pela mãe, mas à pergunta feita por ela mesma; vejamos (turno 04): "O que o carro faz? Pega os brinquedos de Aline". Ora, a criança aí é que faz seu próprio convite à enunciação e responde a ele, mas todo processo se dá na presença da mãe.

Nos fragmentos em que a mãe utiliza a fala em manhês, é possível observar a simulação de uma enunciação atribuída ao bebê. A partir dessa enunciação simulada, são instituídas as bases enunciativas da linguagem que demandam continuamente do infans uma tomada de posição como sujeito. A mãe exerce, com isso, a função de um parceiro enunciativo privilegiado, a quem compete a tarefa de estabelecer com o infans as primeiras trocas linguístico-discursivas, criando cenas dialógicas que incluem desde sempre o bebê.

Na síntese dos apontamentos de Ferreira Júnior (2009: 61), propõese um quadro para ilustrar os papéis e as marcas de pessoa presentes na enunciação que a mãe dirige ao bebê:

\begin{tabular}{|c|c|c|c|c|}
\hline \multicolumn{5}{|c|}{ Quadro funcional da dêixis pessoal na fala materna } \\
\hline \multicolumn{2}{|c|}{$\begin{array}{c}\text { Fala atribuída } \\
\left(1^{\circ} \text { eixo enunciativo }\right)\end{array}$} & \multicolumn{3}{|c|}{$\begin{array}{c}\text { Fala normal } \\
\left(2^{\circ} \text { eixo enunciativo }\right)\end{array}$} \\
\hline Mãe & Bebê & Mãe & & Bebê \\
\hline \multicolumn{2}{|c|}{$\mathrm{SE}^{1 / \mathrm{SE}^{2}} \rightarrow \mathrm{SI}^{1}$} & \multicolumn{3}{|c|}{$\mathrm{Se}^{1 / \mathrm{Se}^{2}} \rightarrow \quad \mathrm{SI}$} \\
\hline & $/ \mathrm{ES}^{2}$ & & & \\
\hline
\end{tabular}

O quadro acima ilustra a existência paralela (embora não simultânea) de dois eixos de enunciação nos quais se veem representados os sujeitos da díade mãe-bebê. A mobilização subjetiva presente nesses dois eixos já constitui um importante indício, na fala materna, do caráter instável e reversível do processo de instalação do sujeito em seu discurso, bem como da própria linguagem em ato. A inversão dos papéis discursivos nos dois eixos enunciativos da fala materna assinala os diferentes lugares atribuídos aos sujeitos na enunciação. 
Desse modo, ao analisar os dados de que dispunha, Ferreira Júnior (2009) afirma que é compreensível o fato de a criança começar a se representar na enunciação com marcas de terceira pessoa, pois na fala materna, sobretudo no primeiro eixo (que possui acentuações prosódicas altas, típicas do manhês, como destacou Cavalcante (1999)), as funções $\mathrm{SE}^{2}$ e ES ${ }^{2}$ recebem bastante ênfase, seja prosodicamente (essa afirmação fica implicada na utilização dessas funções no contexto do manhês, como mostramos) seja pela repetição enfática dessas funções. A conclusão a que chega Ferreira Júnior (2009) é que essas posições constituem recursos discursivos dos quais instintivamente a mãe se vale para sinalizar para o infans qual o lugar que este deve ocupar na cadeia enunciativa, deslocando-o entre esses lugares.

Com base em Benveniste, podemos afirmar que é identificando-se como pessoa que a criança se propõe como sujeito na enunciação. Essa identificação, porém, inicia-se no reconhecimento do lugar que lhe é atribuído pelo parceiro enunciativo, que desde os primeiros momentos de vida da criança dirige a ela a enunciação, emprestando-lhe a voz ao mesmo tempo em que a inquire para ocupar um lugar na cadeia do discurso com vistas à constituição e proposição subjetiva. Na fase inicial da aquisição da linguagem, esse papel enunciativo primário é exercido, geralmente, pela mãe, mas não entendemos por "mãe" um ente biológico e sim uma função interacional assumida por qualquer indivíduo que busque atender às demandas subjetivas do infans. Essa observação amplia o raio de abrangência com que pode ser considerada a função "mãe" na aquisição da linguagem e encontra-se em sintonia com um modelo enunciativo que toma a intersubjetividade como princípio e a linguagem como condição para constituição subjetiva do infans no quadro das relações de trocas enunciativo-discursivas.

A enunciação deflagra modos de constituição e de representação subjetiva, e nesse sentido os índices de pessoa não escapam a essa regra. O uso de um índice subjetivo só encontra seu sentido na relação que estabelece com a instância discursiva onde aparece. Ora, na aquisição da linguagem, ao se propor como sujeito em sua enunciação, a criança deixa transparecer marcas dos diferentes movimentos enunciativos que constituem o mecanismo da aquisição desses indicadores, ao mesmo tempo em que revela os movimentos de sua própria constituição subjetiva. 


\section{Considerações finais}

Nas discussões que fizemos até aqui, vimos que, na perspectiva de Benveniste (1988 e 1989), a ancoragem subjetiva do homem na linguagem está fundamentada na enunciação, que dispõe de bases apropriadas para organização e operacionalização das relações entre os sujeitos. Essas bases estão representadas pelas categorias de espacialidade, temporalidade e pessoalidade, definidas pela instância de discurso que as mobiliza e atualizadas por meio de índices linguísticos específicos. Desse modo, Benveniste se afasta de abordagens que definem as noções de tempo, espaço e pessoa como decalques da realidade extralinguística e considera que os indicadores de subjetividade fazem remissão ao ato enunciativo em que estão inseridos.

Segundo Benveniste, a categoria de pessoa se realiza por meio das classes do verbo e do pronome (e suas subclasses), e a elas juntamos a classe dos nomes, por razões já expostas em nosso texto. Toda a categoria está organizada em duas correlações opositivas: a correlação de pessoalidade e a correlação de subjetividade. No tocante à correlação de pessoalidade, destacou-se que a relação "eu-tu" é marcada pelo traço de pessoa, em decorrência de sua aptidão para participar do ato enunciativo, enquanto que "ele" se caracteriza pela ausência desse traço, exatamente pelo fato de integrar e não participar efetivamente da ação discursiva. É possível perceber, nessa primeira correlação, que pessoa se define na oposição àquilo que está ausente, pois o traço de presença/participação no ato de enunciar que predica "eu-tu" só ganha contraste pela ausência característica da "não-pessoa".

No que diz respeito à correlação de subjetividade, verificamos que Benveniste estabeleceu diferença entre "eu", pessoa propriamente subjetiva, responsável pela proposição do enunciado, e "tu", pessoa não subjetiva, a quem a pessoa subjetiva destina a enunciação. Não há obrigatoriedade de aparecimento explícito de tais índices nos enunciados propostos pela "pessoa-eu" para que seja configurada sua instauração. Ocorre aí uma segmentação entre os índices de pessoa como unidades semióticas (próprias ao sistema da língua) e os índices de pessoa como termos supostos/implicados no exercício enunciativo da língua. Ao se proferir, por exemplo, o pronome "eu", designa-se aquele que fala e ao mesmo tempo está implicado um enunciado sobre esse "eu". De 
maneira semelhante, o "tu" está sempre suposto na enunciação proposta por "eu" e pode ser marcado explicitamente no discurso. Essa diferenciação nos leva a pressupor que não necessariamente os itens referidos na fala do locutor coincidem com as instâncias a que se referem.

Como ressaltamos, sob a perspectiva benvenistiana, é inviável pensar que a categoria de pessoa faz referência a realidades objetivas no mundo extralinguístico. Pelo contrário, os índices de pessoalidade dão prova de que o sujeito deve ser pensado em sua enunciação, lugar em que a relação "eu-outro" é criada e se evidencia, justamente por atualizar a oposição que consta no funcionamento enunciativo da categoria que representam. O modo de organização da categoria de pessoa no exercício enunciativo da língua comporta as condições necessárias e suficientes para a constituição e proposição do homem como sujeito. Na enunciação, os índices linguísticos dos quais o locutor deve se apropriar para transformar a língua (realidade virtual) em discurso são coordenados pelo eixo referencial criado na instância enunciativa em que aparecem empregados e essa instância supõe a existência de um quadro em que as relações intersubjetivas figuram como princípio, meio e fim para a concretização do ato enunciativo.

Para que o locutor preencha o vazio dos índices de pessoalidade, é suficiente tomá-los no uso da língua. Se na língua "eu" e "tu" existem como unidades semióticas virtuais, no discurso esses índices são plenos de referência e sentido. Assim, o mote dos índices de pessoa é dado pela enunciação, que, por isso, engendra as condições intersubjetivas essenciais para que o homem se constitua como sujeito a partir da organização da categoria de pessoa. É essa categoria que veicula a especificidade daquilo que é geral e a generalidade daquilo que é específico: por integrarem o domínio semiótico da língua sob a condição de signos vazios (plano da generalidade), os índices de pessoa só adquirem sentido no exercício enunciativo da língua (plano da especificidade); ao mesmo tempo, os participantes do discurso sempre inscrevem sua especificidade no sistema de relações que extrapola a indicação de qualquer pessoa em particular.

Os desdobramentos que essa perspectiva representa podem ser dimensionados na aquisição da linguagem. Se a categoria de pessoa é organizada no/pelo exercício enunciativo da língua, o tratamento dis- 
pensado à emergência dos indicadores de pessoa na enunciação infantil deve considerar entre as relações entre o infans, a língua e o outro no contexto do discurso. Para que a criança venha a enunciar, é preciso ocupar um espaço nas bases enunciativas da linguagem. Essas bases funcionam como dispositivos que asseguram ao indivíduo condições para compreender a enunciação proposta pelo outro e a capacidade para se propor como sujeito de sua própria enunciação. Cada categoria possui particularidades enunciativo-discursivas que tornam o ato enunciativo um evento sempre único, seja na sua organização formal, seja na sua realização factual.

Os efeitos dessa singularidade se fazem sentir na categoria de pessoa. A efemeridade imposta pela unicidade das bases enunciativas da linguagem é responsável pela imprevisibilidade do ato de enunciar: quando a pessoa se põe a falar, não se sabe o que está por vir, sabese apenas que o que será enunciado não pode ser repetido da mesma forma. Assim, uma tensão constitui a marca do processo enunciativo que condensa em si o arranjo repetível dado pelo sistema da língua e a instituição do sempre novo/irrepetível, ensaiada quando o locutor assume o discurso. Em consequência, as representações atribuíveis às pessoas da cena enunciativa estão igualmente em constante tensão e não podem, por isso, ser reduzidas a formas linguísticas utilizadas explicitamente pelo locutor, mas isso não dispensa o aparecimento dos índices de pessoa na enunciação.

Se a categoria de pessoa está implícita ao processo enunciativo da língua, o locutor caminha em direção à explicitação das representações de pessoa em sua enunciação, e as marcas apropriadas para isso emergem em seu discurso a partir das pistas presentes nas relações estabelecidas com o interlocutor. Cada forma linguística utilizada ou implicitada na fala do locutor para representar os papéis discursivos deflagra um modo novo e singular de constituição e proposição subjetiva.

Recebido em julho de 2014 Aprovado em abril de 2015

E-mails: josetemistocles@yahoo.com.br valdirnf@yahoo.com.br marianne.cavalcante@gmail.com 


\section{Referências Bibliográficas}

Benveniste, Émile. 1988. Problemas de linguística geral I. Campinas, São Paulo: Pontes.

. 1989. Problemas de linguística geral II. Campinas, São Paulo: Pontes.

Cavalcante, Marianne C. Bezerra. 1999. Da voz à língua: a prosódia materna e o deslocamento do sujeito na fala dirigida ao bebê. Campinas-SP. Tese (Doutorado em Linguística) - Instituto de Estudos da Linguagem da Universidade Estadual de Campinas.

FERREIRA JÚNIOR, J. Temístocles. 2009. A dêixis pessoal nas interações mãe-bebê: a constituição do sujeito no processo de enunciação. João Pessoa-PB. Dissertação (Mestrado em Linguística) - Universidade Federal da Paraíba.

Flores, Valdir do Nascimento. 2013. Introdução à teoria enunciativa de Benveniste. São Paulo: Parábola.

JAKobson, R. 1974. Linguística e Comunicação. São Paulo: Cultrix.

SAussure, Ferdinand de. 2006 [1916]. Curso de linguística geral. Trad. Antônio Cheline, José Paulo Paes, Izidoro Blikstein. 27 ed. São Paulo: Cultrix.

Silva, Carmem L. da Costa. 2009. A criança na Linguagem: enunciação e aquisição. Campinas: Pontes Editores. 